\title{
Household Environment and Malaria in Pregnancy in Ibadan, Nigeria
}

\author{
Kabiru K. Salami*, Nneka L. Umego \\ Department of Sociology, University of Ibadan, Ibadan, Nigeria \\ Email: *kabsalami@yahoo.co.uk
}

How to cite this paper: Salami, K.K. and Umego, N.L. (2018) Household Environment and Malaria in Pregnancy in Ibadan, Nigeria. Health, 10, 403-421.

https://doi.org/10.4236/health.2018.104033

Received: January 28, 2018

Accepted: April 17, 2018

Published: April 20, 2018

Copyright $(\odot) 2018$ by authors and Scientific Research Publishing Inc. This work is licensed under the Creative Commons Attribution International License (CC BY 4.0).

http://creativecommons.org/licenses/by/4.0/

\begin{abstract}
Introduction: Malaria in pregnancy, which enormously creates substantial risks for the mother and her fetus, is a public health problem in Nigeria. Design and Methods: Through questionnaire administration, this cross-sectional survey investigates the influence of the household environment on malaria preventive and treatment behaviors among 300 pregnant women in two selected areas of Oyo State, Nigeria. In addition, four focus group discussions and four in-depth interviews were conducted, all between October 2015 and March, 2016. Results: Findings from the study indicate a positive relationship between income level $(P=0.000)$, educational level $(P=0.000)$ and preventive behavior and perception of malaria. There, however, is a negative relationship $(P=0.122)$ between place of residence and number of malaria episodes of the respondents. A high awareness on the cause of Malaria was recorded in this study, while a low awareness on the consequences of malaria infection in Pregnancy was visible. Conclusion and Recommendation: The household environment of pregnant women was found a key predictor in the prevention and treatment of malaria in both rural and urban areas of Oyo State Nigeria. Nationwide programme aimed at reducing malaria especially among pregnant women is needed in Nigeria.
\end{abstract}

\section{Keywords}

Household Attributes, Social Environment, Malaria, Preventive Behavior, Pregnancy, Maternal and Child Health

\section{Introduction}

Malaria, a disease transmitted through female Anopheles mosquito, is estimated to kill more than 1 million people annually, the majority of whom are young children and pregnant women. Nigeria and the Democratic Republic of Congo 
alone account for $40 \%$ of the estimated total of malaria deaths globally [1]. Malaria is unique among diseases because its roots lie so deep within human communities [2]. Malaria has serious economic impacts in Africa, slowing economic growth and development and perpetuating the vicious cycle of poverty. It is truly a disease of poverty afflicting primarily the poor who tend to live in malaria prone rural areas in poorly constructed dwellings that offer few if any, barriers against mosquitoes [3]. Malaria is a parasitic disease which is easily preventable [4], treatable and curable, yet it remains one of the major public health problems in Nigeria [5] [6]. Malaria during pregnancy causes severe maternal illness and anemia, and is also associated with low birth weight among newborn infants, a leading risk factor for infant mortality [7]. The malaria situation in Nigeria is worsening despite the numerous interventions that have been instituted so far. The obstacles to the success of these interventions are socio-cultural, economic and political in nature [8] [9]. A study reported that around $11 \%$ of deaths among pregnant women in Nigeria are caused by malaria [10] [11]. Pregnant women are more susceptible to malaria infections because of their reduced natural immunity and they may develop complications such as fever and severe anaemia. Malaria in pregnancy is mainly due to altered immunity and presence of a new organ called placenta [12].

In areas of low transmission of malaria parasite, with low levels of acquired immunity, women are susceptible to episodes of severe Malaria, which can result in stillbirths or spontaneous abortion or in the death of the mother [13]. In areas of high transmission of the malaria parasite, where levels of acquired immunity tend to be high, women are susceptible to asymptomatic infection, which can result in maternal anemia and placental infection, both of which can subsequently lead to low birth weight.

Unhygienic situations such as around torpid water and pervasiveness of wreckage and wild grass in which many people live create breeding grounds for the mosquito vector and malaria to thrive. The resulting effect has caused a mammoth economic and social burden on the country [14]. Pregnant women have been indicated as being at the greatest risk of contracting malaria [15]; pregnancy reduces a woman's immunity to malaria, and an increased vulnerability of pregnant women to malaria can have devastating consequences on both the women and the unborn child [16].

The environment in and around the home is very critical to people's health. Unhygienic conditions, open drainage systems, lack of disposal system of sewage and solid wastes, water stagnation, canal irrigation, animal sheds, farms nearby and increased building constructions are factors that aid in the breeding of mosquitoes around the home [17]. People's perceptions and understandings of the cause and mode of transmission of malaria have strong implications on the preventive measures of malaria [18]. Socio-economic factors determine where people and communities live, the kind of environment they live in, how they are treated by others, the goods and services they can provide for themselves and what society can provide for them [19]. A people's belief system determines 
greatly how the recognition/definition of malaria is conceived. The belief system forms the basis of categorization of illness into serious, mild or mundane [20]. This also determines the sort of treatment/care that would be sought and the promptness with which it would be sought, or if it would be forestalled or ignored completely [21]. Definition of malaria at household level, as well as treatment of malaria in both mild and severe forms commences at home and outside of the formal healthcare sector.

This study is based on the premise that the environment influences the occurrence of malaria and it advances to explore the relationship between the household environment and malaria among pregnant women in rural and urban communities of Oyo state. The study specifically documents the factors in the environment that promote conducive breeding for mosquitoes, and the relationship between socio-economic status and malaria prevention and treatment. Egbeda and Ibadan north local government areas (LGAs) of Oyo state, the study setting, possess the characteristics of poor housing environment, which may make the setting ideal for the study.

\section{Materials and Methods}

Ibadan, where the study was conducted, is the capital of Oyo state, Southwestern Nigeria. Oyo state consists of 33 local government areas (LGAs) comprising mainly the people of the Yoruba ethnic group. Their main language is Yoruba, which is rich in culture and has a lot of strong belief in the kinship as a means of unity. Other ethnic groups such as Igbo and Hausa can also be found residing and carrying out lawful commercial activities in the State. Ibadan, with 11 LGAs, has 3,232,016 population based on 2014 estimates from population census Office in Ibadan. Ibadan is reputed to be the largest indigenous city in Africa, south of the Sahara. The main occupation of the people of Oyo state is farming. The climate of the state has encouraged farmers to produce different crops. There are eight government farm settlements and three vast cattle ranches in Oyo states. There are tertiary institutions in the city including; the University of Ibadan, Lead City University and the Polytechnic of Ibadan. There is University College Hospital-a teaching hospital of the University of Ibadan, maintained by the federal government of Nigeria, Adeoyo State hospital maintained by the State government and many private hospitals in the city. The city is also endowed with many research institutes among which are International Institute for Tropical Agriculture (IITA) and Nigeria Institute for Social and Economic Research (NISER).

With a cross-sectional survey design, this study describes the relationship between household environment and malaria experience among rural and urban dwelling pregnant women in Ibadan Nigeria. A multistage sampling technique was used to select respondents from Egbeda and Ibadan North LGAs. Respondents were selected from six communities of the two LGAs. In Ibadan North, data were collected from Agbowo, Mokola and Bodija areas while in Egbeda; Awaye, Osegere and Olukeye communities were sampled for data collection. 
From each cluster, respondents were then purposively selected to participate in the study. Selection for the sample was based on respondents' meeting the study population criteria and expressing willingness to participate in the study. Three hundred and fifteen pregnant women were traced for participation in the study. However, copies of questionnaire for eight pregnant women were poorly filled, while seven women dropped out of the interview on the ground that they were not comfortable discussing their pregnancy which they had "searched" for over a long time. Overall, only 300 copies of questionnaire were administered to the respondents in Ibadan North LGA (257 pregnant women) and those in Egbeda LGA (43 pregnant women) completely and analysed. In addition, four focus group discussions (FGDs) sessions, with at least eight members in each session, were carried out among young and older mothers in the two LGAs, while four in-depth interviews (IDIs) were conducted in each LGA among chief nursing officers and pharmacists in the studied communities. Members of FGDs were sourced from across the community to allow for wider coverage while participation was voluntary. During the study, the ethical principles and rules involved in dealing with human subjects on social issues were strictly observed. The consent of; the pregnant women, FGD members and IDI participants was received individually through their signature or thumbprint appended on informed consent form. The confidentiality of the respondents and the informants was protected by gathering the information anonymously, while the informants' names or any other information that could reveal their personal identity was not sought in the course of the study. Participation in the study was also voluntary. Resulting quantitative data obtained from the questionnaires were cleaned, coded and analyzed using univariate, bivariate and multivariate levels of analysis through Statistical Package for Social Sciences (SPSS) software version 15. The qualitative data was tape-recorded during the interviews with the permission of the participants, later transcribed and finally analyzed using content analysis. The following section presents the results from the study.

\section{Results}

Overall, the women who were pregnant as at the time of study were surveyed from urban $(n=257)$ and rural $(n=43)$ communities. The age of the respondents ranged between 15 and 45 years with a mean age of 28.6 years while the standard deviation is approximately 1.3 . The majority (75.7\%) of the study population was Christians, while the rest were Muslims (24.3\%). Respondents were either urban dwellers $(85.7 \%)$ or rural dwellers $(14.3 \%)$, all of whom were either married $(99 \%)$, single $(0.7 \%)$ or widow $(0.3 \%)$ as at time of survey. The occupational distribution of the respondents showed that slightly below average were traders/business women. Also a large majority (85.3\%) of the respondents was Yoruba, followed by 27 (9.0\%) Igbo and one (0.3\%) Hausa. Other respondents (5.4\%) such as Egede, Nupe, Bini and Ibibio, were migrants from minority groups of the country. In all, slightly above half, 166 (55.3\%) of the respondents 
had tertiary education, followed by secondary education with 95 (31.7\%) of the respondents and $31(10.3 \%)$ of the respondents with primary education. Eight (2.7\%) respondents reportedly had no formal education. When malaria experience of the respondents was sourced to document malaria episodic rates in their current pregnancy, more than half $(58.4 \%)$ of the respondents had, at least, had one episode of Malaria in their current pregnancy while $6.3 \%$ (urban $=15$; rural $=4$ ) reportedly not sure. In both urban and rural communities, $40.7 \%$ (urban $=102$; rural $=20), 16.7 \%($ urban $=40$; rural $=10)$ and $1.0 \%($ urban $=2$; rural $=$ 1) women reported that they had malaria episode once, twice and thrice respectively in their pregnancy. Only $35.3 \%$ (urban $=98$; rural $=8$ ) women did not experience any malaria episode in their pregnancy period. Overall, analysis of malaria episode by place of residence through a Pearson chi square showed a significant relationship $(\mathrm{P}$ value $=0.122)$.

\subsection{Predictors of Mosquito-Breeding Behavior in and around the Household}

This study documents the behavior of the respondents that promote mosquito-breeding in and around the household. Hence, this study documents the sources of water, water storage facilities, toilet facilities, drainage systems and refuse disposal systems of the household members. Table 1 shows that water was mostly drawn by majority (38.3\%) from uncovered well in their immediate environment, and poor water storage facilities was reported. Although $62.7 \%$ of the respondents reportedly stored their own water in covered containers, other respondents who utilized rubber tanks (21.0\%), basins/buckets (18.7\%), rubber drums $(16.3 \%)$ and clay pots $(1.3 \%)$ indicated these storage facilities as uncovered. Toilet facilities available to the respondents ranged from individual flush toilets (54\%) to shared-flush toilet (26\%), pit latrines (10\%) bush (8.3\%) and use of buckets (1.3\%). More than half (55\%) of the respondents were observed to have open gutter with stagnant water around their houses while $28.3 \%$ reportedly poured water on the ground around their house. Refuse disposal system in the households was also reported with majority (39.3\%) reportedly use regular refuse collector, followed by covered dustbin (28\%), dumping of refuse at backyard (11.6\%) and use of public ground (16.3\%). Likewise, the respondents were aware of need to protect themselves from mosquito bites hence, window nets were found in $77.3 \%$ households, bed nets were owned by $48.7 \%$ households and $50.3 \%$ respondents had ceilings in their households. The use of insecticides was reported by $53 \%$ of the respondents, while $25.3 \%$ of the respondents also hanged screened nets on their doors as shown in Table 1.

\subsection{Commercial and Domestic Activities Performed around the House}

In all, $39.7 \%$ of the respondents had commercial activities running around the household environment. Retail shops were found in 34 (11.3\%) households; 
Table 1. Predictors of mosquito-breeding behavior in and around the household of the respondents in rural and urban residence $(\mathrm{N}=300)$.

\begin{tabular}{|c|c|c|c|}
\hline \multirow{2}{*}{ Predictors } & \multicolumn{2}{|c|}{ Place of residence } & \multirow{2}{*}{ Percentage } \\
\hline & Urban & Rural & \\
\hline \multicolumn{4}{|l|}{ Source of water } \\
\hline Tap & 56 & 31 & 29.0 \\
\hline Well (uncovered) & 114 & 1 & 38.3 \\
\hline Borehole & 78 & 10 & 29.3 \\
\hline Tanker trucks & 6 & 0 & 2.0 \\
\hline Springs/streams & 0 & 1 & 0.3 \\
\hline Water runs in the house & 3 & 0 & 1.0 \\
\hline \multicolumn{4}{|l|}{ Storage facilities } \\
\hline Open clay pots & 2 & 2 & 1.3 \\
\hline Open rubber tanks & 63 & 0 & 21.0 \\
\hline Open basins/buckets & 21 & 5 & 18.7 \\
\hline Closed containers & 152 & 36 & 62.7 \\
\hline Open rubber drums & 19 & 0 & 16.3 \\
\hline \multicolumn{4}{|l|}{ Toilet facilities } \\
\hline Individual flush toilet & 159 & 3 & 54.0 \\
\hline Shared flush toilet & 73 & 6 & 26.3 \\
\hline Pit latrine & 21 & 9 & 10.0 \\
\hline Bucket/pail system & 2 & 2 & 1.3 \\
\hline Bush/bare ground & 2 & 23 & 8.3 \\
\hline \multicolumn{4}{|l|}{ Drainage systems } \\
\hline Open gutter & 158 & 7 & 55.0 \\
\hline Sewage system & 84 & 1 & 28.3 \\
\hline Poured water on the ground & 15 & 35 & 16.7 \\
\hline \multicolumn{4}{|l|}{ Refuse disposal system } \\
\hline Covered dustbin & 80 & 4 & 28.0 \\
\hline Backyard & 18 & 17 & 11.7 \\
\hline Public ground & 28 & 21 & 16.3 \\
\hline Regular refuse collector & 118 & 0 & 39.3 \\
\hline Public incinerator & 3 & 0 & 1.0 \\
\hline Burning & 10 & 1 & 3.7 \\
\hline
\end{tabular}

hairdressing salon and operation of grinding machines for pepper, both involving use of water, were found in $6.7 \%$ household environments each. Ten (3.3\%) households were raising poultry in their immediate environment while 20 (6.7\%) households actually engaged on commercial farming around their building. Bakery was found in seven (2.3\%) household environments, fashion designer shops were found in four (1.2\%) environments and finally four (1.2\%) household environments had borehole water which was made available to people to 
fetch with payments. Also, majority (70.7\%) of the respondents actually reported staying outside the house for different activities in the previous night before the survey. In all, 192 (64\%) respondents stayed outside the house to "play and relax", $8.7 \%$ of the respondents "cooked outside for the household members' consumption", while $4.7 \%$ respondents "swept the compound before going to bed". Five (1.7\%) respondents were "fetching water" while two $(0.7 \%)$ of the respondents were "washing clothes outside the house" the previous night before the survey. Only, sixty-one (20.3\%) respondents reportedly not stayed outside the house the previous night before the survey.

\subsection{Perception of Malaria among Pregnant Women}

Level of awareness of the causes (86.3\%) and symptoms (72.0\%) of malaria was found very high. Respondents indicated that mosquitoes and dirtiness (86.3\%) were the major causes of malaria, and that headache (39.3\%), fever and convulsion (32.7\%) were the major symptoms of malaria. Knowledge of the agent of malaria-disease transmission was also demonstrated at the group discussions. For instance, members of a group discussion in one of the urban groups emphasized mosquito as a major agent of malaria: " $A$ person can catch malaria if the person allows mosquito to bite her, mosquito is the major cause of malaria (URBANIFGD1)" while the perceived causes of malaria and the awareness of its prevention were further reinforced by discussants in a rural group discussion: "Pregnant women should keep their surroundings clean because of mosquito, which is the root cause, by cutting weeds around the house (RURAL/FGD2)". Discussants even traced the process of symptom presentation of malaria among which headache and fever were ranked higher than other symptoms. A discussant in the urban group noted that: "Malaria starts with headache first, before it moves to other things like weakness of the body, loss of appetite and body pains (URBANIFGD2)". Poor perception of the consequences of malaria was however expressed among group discussants. Respondents also attached high priority to consequences such as; complications and convulsions (32.3\%) and miscarriage $(30.3 \%)$ and the possibility of death (11.3\%). Data on perceived seasonal variation of malaria episode showed that Malaria was perceived as being common during dry season by $112(37.3 \%)$ of the respondents than during wet/raining season (31\%). Only twenty-seven (9\%) of the respondents considered it a year-round illness while 68 (22.7\%) of the respondents reportedly had no idea. Narratives of the group discussions indicate that many respondents still perceived malaria as a normal and common illness that occurs naturally notwithstanding preventive measures. For instance, even discussants in an urban group consider malaria as a mild and mundane illness that cannot kill: "If malaria wants to come it will come; it is natural. For some women, it is by luck that malaria does not affect them, while others get malaria easily (URBAN FGD2)".

\subsection{Susceptibility to Malaria}

Perceived susceptibility was reported by the respondents. More than half 
$(52.1 \%)$ of the respondents indicated that they were susceptible to malaria infection. Data on susceptibility to malaria by different categories of people and by place of their residence showed attribution to: pregnant women by $52.1 \%$ (urban = 140 ; rural $=16)$ of the respondents; children by $32.3 \%$ (urban $=84$; rural $=13$ ) of the respondents; aged by $11.0 \%$ (urban $=27$; rural $=6$ ) and adult by $3.0 \%$ (urban = 6 ; rural $=3)$. Only five $(1.7 \%)$ respondents from rural location were not sure. There is a significant relationship between the category of people who perceived susceptibility to malaria and their places of residence (P-value: 0.000 ). Interviews with a chief nursing officer highlighted the rate of cases of pregnant women with malaria cases that she had seen in the facility in the previous two weeks: "We don't usually keep record of that here, but per day at least we see about ten cases of pregnant women who are infected with malaria. Malaria is not an easy case and when it affects a pregnant woman it should not be taken lightly, because it can cause placental problems (IDI/CNO/URBAN)". Although most pregnant women were aware of their vulnerability, discussants among older mothers revealed an erroneous belief that skin colour is a determinant of vulnerability to malaria. Older women were of the opinion that people with fair complexion are more prone to malaria than dark-skinned people: "There is no one who can't have malaria, but fair-skinned people have malaria more. Dark-skinned people don't use to have malaria because it will not show on them (FGD/RURAL2)".

\subsection{Malaria Preventive Behavior in Pregnancy}

Table 2 indicates that a heightened awareness of the benefits of antenatal care was shown by respondents in both rural and urban areas as large majority (94\%) of the pregnant women were registered attendees of ANC clinics. Attendance at ANC was considered an opportunity to determine appropriate antimalarial for women based on their gestational age:

In our clinic we usually recommend drugs for women based on the age of their pregnancy. If a woman has malaria in her first trimester we recommend Amodiaquine, and ask her to come back for checkup in a week's time, but if it's second trimester, we give Artesunate and Artemether combination, that time the pregnancy is formed (IDI/CNO/URBAN).

A wide gap, however, exists between rural and urban areas in the use of bed nets as a preventive behavior against malaria. Table 2 indicates that most pregnant women did not use bed nets in their households. This is more evident in the rural areas with only very few $(n=7)$ of them reportedly used bed nets. Interviews conducted in the rural setting examined the preventive measures undertaken against malaria by pregnant women at home and confirmed mosquito nets: “ $A$ pregnant woman should try as much as possible to keep her home neat and also sleep under mosquito net, to stop malaria in her condition, and then leave the rest to God (IDI/ RURAL1)". This was also confirmed in another IDI conducted in the urban: "In fact, for a pregnant woman to have good health, she 
Table 2. Distribution of preventive behavior of respondents by place of residence $(\mathrm{N}=$ 300).

\begin{tabular}{|c|c|c|c|}
\hline \multirow{2}{*}{ Malaria preventive behavior } & \multicolumn{2}{|c|}{ Place of residence } & \multirow{2}{*}{ Percentage } \\
\hline & Urban & Rural & \\
\hline \multicolumn{4}{|l|}{ ANC attendance } \\
\hline Yes & 251 & 31 & 94.0 \\
\hline No & 6 & 12 & 6.0 \\
\hline Total & 257 & 43 & 100.0 \\
\hline \multicolumn{4}{|l|}{ IPT treatment } \\
\hline ACTs & 37 & 0 & 12.3 \\
\hline SPs & 20 & 0 & 6.7 \\
\hline Chloroquine & 15 & 0 & 5.0 \\
\hline Ferrous, B. complex and Folic acid & 82 & 7 & 29.7 \\
\hline ACTs and SPs & 3 & 1 & 1.3 \\
\hline None & 99 & 34 & 44.3 \\
\hline Not sure & 1 & 1 & 0.7 \\
\hline Total & 257 & 43 & 100.0 \\
\hline \multicolumn{4}{|l|}{ Usage of bed nets } \\
\hline Not applicable & 121 & 36 & 52.3 \\
\hline Anytime we sleep/every day at night & 104 & 6 & 36.7 \\
\hline Once in a while & 32 & 1 & 11.0 \\
\hline Total & 257 & 43 & 100.0 \\
\hline
\end{tabular}

ANC = Antenatal Care, IPT = Intermittent Preventive Treatment, ACT = Artemisinin-Based Combination Therapy, SP = Sulfadoxine Pyrimethamine.

should eat good food, attend antenatal, clean her environment and make sure she sleeps under mosquito nets (IDI/ URBAN)".

\subsection{Malaria Treatment Methods in Pregnancy}

Half (50\%) of the pregnant women in this study indicated their awareness of the fact that formal healthcare institutions were the best option in treating ailments that affect them during pregnancy. It was also evident from the results that self-medication $(10.3 \%$; urban $=16$, rural $=15)$ is still rampant among the respondents, just as $2.3 \%$ (urban $=3$, rural $=4$ ) of the pregnant women patronized chemists for their treatment. Use of homemade brews $(0.3 \%)$ by one respondent in urban location and use of traditional healers $(1.3 \%$; urban $=3$, rural $=1)$ were other treatment methods mentioned by the respondents. In all, 35.7\% (urban = 98 , rural $=9$ ) pregnant women indicated no preference at all. A relationship test between preferred treatment methods and place of residence in this study showed a significant positive relationship $(\mathrm{P}$-value $=0.000)$ between the two variables. Significantly, there was a difference in the number of pregnant women who utilized the hospitals for treatment and the place of residence. 


\subsection{Malaria Preventive Behavior and Gestational Age by Trimesters}

Malaria preventive behavior of pregnant women such as: Registration at ANC, use of bed nets and IPT treatment by trimesters are shown in Table 3. Table 3 shows that large majority (94\%) of the pregnant women in all trimesters registered for antenatal care. Chi-square test on trimester and registration at antenatal clinic showed a significant relationship (P-value 0.000 ). Result shows that most pregnant women in their third trimesters had registered for antenatal clinic. Use of bed nets at different trimesters was also adopted by women in their second and third trimesters than those women in their first trimester. Also, as the study recorded that majority $(49.4 \%)$ of the respondents are in their second and third trimesters, possibility of greater precautions exist among them than those in their first trimester. This difference was further confirmed by a chi-square test which indicated a significant $(\mathrm{P}$-value $=0.008)$ relationship between trimester and use of bed nets. Reception of IPT was of concern as shown in Table 3 that though a good number of pregnant women at all trimesters received IPT treatment, nearly half of the respondents still did not receive any preventive treatment $(42.7 \%)$, or received wrong/unapproved treatment (5\%). However, no relationship $(\mathrm{P}$-value $=0.198)$ was found between IPT treatment and the different trimesters.

\subsection{Malaria Treatment Behavior and Gestational Age by Trimesters}

Table 3 also indicates that more than half of the respondents had malaria episode during their current pregnancy and had sought for treatment at the formal healthcare facilities. This was shown across all the trimesters. Other treatment methods were also utilized by other respondents across trimesters.

The tendency that malaria occurs at any stage of pregnancy was confirmed by a Chief Nursing Officer (CNO) interviewed. For instance, the CNO attributed malaria in pregnancy to the nature of the environment:

...it depends on their living environment, because you can't link malaria episode to first or second trimester. Those that are prone to malaria are those who do not care about what is happening in their surroundings. How tidy is their surroundings? So it is not by the trimesters but by the people's environment where they live (IDI/CNO).

The opinion of the CNO was not totally accepted by all health personnel as explained by a nurse that the first trimester is often a time when women are exposed to worst experience of malaria episode:

The first trimester is usually the worst period for any pregnant woman to have malaria, and so at first trimester women are the ones that malaria catches the most (IDI/RURAL).

The delay in seeking medical care when a pregnant woman contracts malaria 
Table 3. Distribution of respondents by preventive and treatment behavior and trimester $(\mathrm{N}=300)$.

\begin{tabular}{|c|c|c|c|c|}
\hline \multirow{2}{*}{ Preventive Behavior } & \multicolumn{3}{|c|}{ Trimester } & \multirow{2}{*}{ Percentage } \\
\hline & First & Second & Third & \\
\hline \multicolumn{5}{|l|}{ Registration at ANC } \\
\hline Yes & 21 & 125 & 137 & 94.3 \\
\hline No & 2 & 9 & 5 & 5.7 \\
\hline No response & 1 & 0 & 0 & 0.3 \\
\hline \multicolumn{5}{|l|}{ Usage of Bed Nets } \\
\hline Anytime we sleep & 7 & 53 & 50 & 36.7 \\
\hline Once in a while & 4 & 12 & 13 & 9.7 \\
\hline Not applicable & 12 & 65 & 78 & 51.7 \\
\hline No response & 3 & 3 & 0 & 2.0 \\
\hline \multicolumn{5}{|l|}{ Reception of IPT Doses } \\
\hline ACTs & 3 & 20 & 15 & 12.7 \\
\hline SPs & 1 & 8 & 11 & 6.7 \\
\hline Chloroquine & 2 & 8 & 5 & 5.0 \\
\hline Ferrous, B. complex, Folic acid and blood capsules & 3 & 39 & 33 & 25.0 \\
\hline ACTs and SPs & 0 & 1 & 3 & 1.3 \\
\hline None & 14 & 56 & 58 & 42.6 \\
\hline Not sure & 0 & 2 & 4 & 2.0 \\
\hline No response & 6 & 4 & 4 & 4.7 \\
\hline \multicolumn{5}{|l|}{ Episode of Malaria } \\
\hline Once & 10 & 51 & 60 & 40.7 \\
\hline Twice & 3 & 20 & 27 & 16.7 \\
\hline Thrice & 0 & 2 & 1 & 1.0 \\
\hline Can't remember & 3 & 9 & 7 & 6.3 \\
\hline Not at all & 7 & 52 & 46 & 35.3 \\
\hline \multicolumn{5}{|l|}{ Treatment Method } \\
\hline Self-medication & 3 & 9 & 19 & 10.3 \\
\hline Hospital & 12 & 71 & 66 & 49.7 \\
\hline Chemists & 1 & 0 & 6 & 2.3 \\
\hline Traditional healers & 0 & 3 & 1 & 1.3 \\
\hline Homemade brews & 0 & 0 & 1 & 0.3 \\
\hline Not applicable & 16 & 51 & 48 & 38.3 .3 \\
\hline \multicolumn{5}{|l|}{ Length of Time before Treatment } \\
\hline 12 hours & 4 & 5 & 8 & 5.7 \\
\hline A day & 4 & 42 & 35 & 27.0 \\
\hline Two days & 5 & 31 & 40 & 25.3 \\
\hline Three days & 2 & 7 & 6 & 5.0 \\
\hline A week & 0 & 0 & 1 & 0.3 \\
\hline Not sure & 0 & 1 & 3 & 1.3 \\
\hline Not applicable & 9 & 49 & 48 & 35.3 \\
\hline
\end{tabular}

ANC $=$ Antenatal Care, IPT $=$ Intermittent Preventive Treatment, ACT $=$ Artemisinin-based Combination Therapy, SP = Sulfadoxine Pyrimethamine. 
is also a crucial issue examined in this study. Results showed that majority still see malaria as a mild illness that "will pass away soon enough". The delay is portrayed in this study as Table 3 indicates that pregnant women in all the trimesters waited for at least two days after malaria episode before they sought for medical care. In most cases, just few differences exist on time-lag before treatment among the different trimesters. This is further confirmed in the chi-square test which showed no significant relationship $(P$ value $=0.075)$ between trimesters and time before treatment. A linear regression of socio-demographic characteristics of the respondents and a dependent variable prevention score of malaria was carried out. The independent variables included: age, education, occupation, religion, gestational age in months, marital status and residential area as shown in Table 4. The prevention score was computed with preventive measures such as use of bed nets, sanitation of facilities in the household, reception of IPT treatment and registration for ANC. The results indicate that out of all the socio-demographic characteristics, only age, education, religion and residential area influenced the preventive behavior that was adopted by the respondents.

Table 5 shows the influence that the income level of the respondents has on their perception and prevention of malaria. The results from Table 5 reveal that at the $5 \%$ level of significance, no significant relationship $(\mathrm{P}=0.332)$ exists between income level and respondents' perception of malaria. It also shows that there is a significant positive relationship $(P=0.000)$ between the income level of the respondents and their prevention of malaria. Results indicate that the usage/uptake of malaria preventive measures is often influenced by the income level of pregnant women and their households while low income translates to poor living standards. Also, the higher the income level, the higher the preventive behavior taken against malaria.

\section{Discussion}

A good number of the respondents at both urban and rural locations had at least one episode of malaria during their current pregnancy as at the time of this research. The urban malaria experience may not necessarily be due to the lack of accessibility and availability of health care facilities but may be consistent with

Table 4. Regression on the respondents' socio-demographic characteristics and prevention score of malaria.

\begin{tabular}{cccc}
\hline Variables & Standard Coefficient & $\mathrm{T}$ & P-values \\
\hline Age & 0.087 & 2.400 & 0.017 \\
Education & 0.010 & 2.004 & 0.046 \\
Gestational age in months & 0.009 & 0.154 & 0.878 \\
Occupation & -0.023 & -0.408 & 0.683 \\
Religion & -0.115 & -2.037 & 0.043 \\
Marital status & -0.042 & 0.727 & 0.468 \\
Residential area & 0.383 & -4.010 & 0.000 \\
\hline
\end{tabular}


Table 5. Anova test on perception score, prevention score and income level.

\begin{tabular}{ccccc}
\hline & & Degree of Freedom & F & P-value \\
\hline $\begin{array}{c}\text { Perception score } \\
\text { of malaria }\end{array}$ & Between groups & 14 & 1.131 & 0.332 \\
& Within groups & 286 & & \\
Prevention score & Total & 300 & 3.551 & 0.000 \\
Of malaria & Between groups & 14 & & \\
& Within groups & 286 & & \\
\hline
\end{tabular}

findings that both rural and urban areas are associated with increased risks of malaria for both epidemiological and socio-economic reasons [22]. Also households located in low-income slum areas were found to be suffering from frequent bouts of mosquito-borne disease [23].

The environment in and around the home is more critical to malaria experience. Notwithstanding the awareness on mosquito breeding and malaria, this study demonstrated that not much is often done in the household environment to curb the disease. Unhygienic conditions, open drainage systems, inadequate disposal system of sewage, water stagnation, open water storage systems were observed in the households visited in the course of this study. As these factors are promoters of mosquito breeding in the household, their prevalence also tends to confirm the previous studies [11] [24], where it was found that the environment in and around the home was very crucial to the individual's health. A previous study [24] also established that factors that hinder quality home environment include; open drainage systems, lack of disposal system, water stagnation, animal sheds and unhygienic conditions. A study in Uganda observed that the high rate of malaria episodes among its respondents was attributed to the poor household environment [25]. In addition, a good number (41\% and 75\% respectively) of the respondents in the same study had water pools and vessels that were uncovered for potential mosquito breeding [25].

The commercial activities around the houses in this study have tendency of promoting conducive environment for mosquito breeding. Water poured on the ground, as reported by $28.3 \%$ and those gathered from the commercial activities around the house can actually gather in puddles thereby creating conducive breeding ground for mosquitoes. Similar commercial activities were documented in a study that focused on human practices and breeding of mosquitoes in Anambra state, Nigeria [26]. The same study [26] documented that the commercial activities of cassava fermenting and preparation for sale around the household environment, actually created conducive environments for the breeding of mosquitoes. Another study conducted on predictors of malaria association found that man-made activities such as brick making and swamp reclamation created more human-made aquatic habitats for the anopheles mosquitoes and respondents also perceived night-biting of mosquitoes as a nuisance and not 
something considered dangerous [20]. Whereas, respondents in this study reportedly stayed outside the house at night, with the risk of exposure to mosquito bite, a recent study on biting patterns of anopheles mosquito, also found that activities performed at night by man exposed them to a lot of mosquito bites, as respondents in their study engaged in night fishing [27].

Unequal level of educational attainment in urban and rural locations reveals that most of the women in rural areas have primary and secondary education while urban dwellers have more tertiary education. This just goes further to portray the influence of level of development and poor amenities that is evident in the rural parts of the country. Preventive behavior that is practiced by women is influenced by their level of education [28] [29]. It can further be deduced then that the level of prevention of diseases will be lower in the rural areas.

Income level also influences the malaria preventive and treatment behavior of pregnant women. Human health is determined not only by contact with the microbes and toxins that directly cause illness/by organ system failure, but also by other biological and social factors. In this study, findings revealed that financial constraint was one of the reasons why women did not get the adequate care and protection they needed when they were infected with Malaria during pregnancy. Rural pregnant women were worse off, as they did not earn enough to cater to promote their healthcare. This finding is also consistent with previous findings that income level in the household determined the type of preventive measures that were taken [28] [29] that rural poor households were less likely to sleep under bed nets than their rich urban counterparts [30]; and that the demand for preventive healthcare is influenced by income level [31]. The lower income levels reported for rural women may probably be due to the fewer economic opportunities available as well as the generally low income level in rural areas. Most rural women were involved in small-scale agribusiness and other primary production pursuits and petty trading, which yield very low earnings. Measures to treat and prevent malaria among the poor are financially and physically not accessible [6].

Increased awareness on the use of insecticide treated nets as the major preventive measure against mosquito bites especially during pregnancy was exemplified from both qualitative and quantitative data in this study. Malaria preventive practices reported by respondents in this study include; the use of window and bed nets, insecticides, screened doors and ceiling. Amongst all these, bed nets (especially insecticide-treated nets) is the most effective preventive method that should be adopted especially during pregnancy [32] [33]. It is also the preventive facility that most interventions against malaria have focused on. Another preventive measure used in the fight against Malaria in pregnancy is the intermittent presumptive treatment (IPT) which is meant to be given to all pregnant women during antenatal care. Findings in this study revealed that a good number of the pregnant women did not receive this treatment and this was due to the issue of accessibility, availability and financial constraints. In addition, the cur- 
rent prevention of malarial disease in pregnancy relies on two main strategies [34]: providing pregnant women with insecticide-treated bed nets (ITN) and intermittent presumptive treatment (IPT) with antimalarial medications.

Findings in this study clearly projected the level of knowledge of the causes and symptoms of Malaria. A good number of the respondents attributed the cause of Malaria to the bite of Mosquitoes and also headache and fever to be the chief symptoms. This is in line with findings on the knowledge, perceptions, and misconceptions about malaria, that most of the respondents attributed malaria to mosquito bites and identified the major symptoms as headache and fever [35] [36]. Respondents in this study also highlighted other causes of malaria such as excessive sunlight, unbalanced diet and eating unripe fruits. These other causes indicated a low knowledge of malaria causation. Obol et al. [37] also confirmed the lack of knowledge in their study when a good number (50\%) of the respondents reported jaundice to be the major consequence of malaria infection. Chukwurah [11] study on the knowledge, attitude and practices on Malaria prevention further confirms this low knowledge on consequences of malaria.

The risk of malaria depends on if one is bitten by an infected mosquito. The risk of infection also depends on one's level of immunity. Pregnant women constitute the main adult risk group for malaria and $80 \%$ of deaths due to malaria in Africa occurs in pregnant women and children below 5 years [15]. This was made evident in this study, as a good number of the pregnant women had at least one episode of Malaria in their current condition. This experience manifested in all trimesters. Prevention of malaria in pregnancy can be looked at in terms of antenatal care attendance, reception of IPT treatment and the use of bed nets. Findings in this study revealed that though pregnant women were aware of preventive measures to take against Malaria, women in the rural areas did not have access to these measures. Amponsah's study [30] also reported similar findings that rural residents were less likely to practice preventive behavior than those in the urban areas. Aluko et al. [38] also indicated that positive attitude towards the use of ITNs is significantly influenced by an individual's place of residence. This could be due to lack of accessibility to the nets, and in some cases availability, as most interventions on this do not get to rural areas.

There was a high turnout in the attendance at ANC clinics, especially by women who were in their second and third trimesters. This exemplifies outcome of successful health education programs. At the same time, it could be due to the nearness to their delivery time and therefore their perceived preventive benefits were increased than those who were in their first trimesters. Other results in this study revealed that though attendees at the ANCs were high, only very few of them actually got the IPT treatment, hence, a good number of the respondents sought for alternative means during malaria infection. This still concurred with findings of a study [39] which reported that treatment of illness in Nigeria usually commences in the household with self-medication. This could be due to low perceived benefits in a particular source of treatment or perceived threat about the illness itself. 


\section{Conclusion}

Malaria remains a major threat to health in Nigeria. Most households in rural and urban areas are knowledgeable about the causes and symptoms of malaria, though knowledge on the consequences of malaria is very low. In this study it was shown that poverty is a major barrier to adequately preventing and treating malaria and also a major deterrent for pregnant women in patronizing health centers. There were no much differences in the treatment methods of malaria adopted by pregnant women in both rural and urban areas and across trimesters. To ensure more pregnant women actually receive more of the IPT treatment and the immunizations meant for them, policies can be created on household administration of these drugs. There is also a need for behavioral change in the perceived beliefs of pregnant women about the severity of malaria infection; this will help in the development of an evidence-based intervention towards eradication of malaria in pregnancy.

\section{Significance for Public Health}

This study has pointed out that malaria is a major health concerns for women in pregnancy. The household attributes including the environment where pregnant women live play significant influence on their health status during the conception. Promoting conducive social and cultural environment should be a major point of fact which public health practitioners would have to take into consideration when designing maternal and child health programmes and campaign for vulnerable groups such as pregnant women in Nigeria and some African countries.

\section{Competing Interest}

The authors declare that they have no competing interests.

\section{Authors' Contributions}

KKS, and NLU made substantive intellectual contributions to various stages that led to this article, including the conception, design and implementation of the study from whence this article is generated. Analysis and interpretation of data in this study was carried out by KKS. The draft copy of the article was prepared by KKS, with input from NLU. Both authors agreed with the content of the article and approved the final manuscript.

\section{Acknowledgements}

We are grateful to respondents who participated in the study for giving their time to respond to interviews.

\section{References}

[1] Gueneuc, A., Deloron, P. and Bertin, G.I. (2017) Usefulness of a Biomarker to Identify Placental Dysfunction in the Context of Malaria. BioMed Central. Malaria 
Journal, 16, 11. https://doi.org/10.1186/s12936-016-1664-0

[2] Singh, R., Musa, J., Singh, S. and Ukatu, V.E. (2014) Knowledge, Attitudes and Practices on Malaria among the Rural communities in Aliero, Northern Nigeria. Journal of Family Medicine and Primary Care, 3, 39-44. https://doi.org/10.4103/2249-4863.130271

[3] UNICEF (2014) Malaria: UNICEF’s Response 2014. https//www.unicef.org/health/index_malaria.html

[4] WHO (2014) World Malaria Report. http://www.who.int/malaria/world_malaria_report_2014

[5] Omole, M.K. and Onademurea, O.T. (2010) A Survey of Anti-Malaria Drug Use Practices among Urban Dwellers in Abeokuta, Nigeria. African Journal of Biomedical Resources, 13, 1-7.

[6] Udoudo, M.G.M. and Umoh, G.S. (2016) Can Government Deliver Quality Rural Healthcare? Empirics on Malaria Prevalence and Control in Nigeria. Asian Journal of Economic Modelling, 4, 70-81. https://doi.org/10.18488/journal.8/2016.4.2/8.2.70.81

[7] Okpere, E.E., Enabudoso, E.J. and Osemwenkha, A.P. (2010) Malaria in Pregnancy. Nigerian Medical Journal, 51, 109-113.

[8] Amoran, O.E. (2013) Impact of Health education Intervention on Malaria Prevention Practices among Nursing Mothers in Rural Communities in Nigeria. Nigerian Medical Journal, 54, 115-122. https://doi.org/10.4103/0300-1652.110046

[9] Tambo, E., Adedeji, A.A., Huang, F., Chen, J., Zhou, S. and Tang, L. (2012) Scaling up Impact of Malaria Control Programmes: A Tale of Events in Sub-Sahara Africa and Peoples' Republic of China. Infectious Diseases of Poverty, 1, 7.

https://doi.org/10.1186/2049-9957-1-7

[10] Olaseinde, C.H., Ojurongbe, O.O., Akinjogunla, O.J., Egwari, L.O. and Adeyeba, A.O. (2015) Prevalence of Malaria and Predisposing Factors to Anti-Malarial Drug Resistance in Southwestern Nigeria. Research Journal of Parasitology, 10, 92-101. https://doi.org/10.3923/jp.2015.92.101

[11] Chukwurah, J.N., Idowu, E.T., Adeneye, A.K., Aina, O.O., Agomo, P.U. and Otubanjo, A.O. (2016) Knowledge, Attitude and Practice on Malaria Prevention and Sulfadoxine-Pyremethamine Utilization among Pregnant Women in Badagry, Lagos State, Nigeria. Malaria World Journal, 7, 1-6.

[12] Singh, S., Madaki, A.J.K., Jiya, N.M., Singh, R. and Thacher, T.D. (2014) Predictors of Malaria Infebrile Children in Sokoto Nigeria. Nigerian Medical Journal, 55, 480-485. https://doi.org/10.4103/0300-1652.144701

[13] Lopez-Perez, M., Pacheco, M.A., Buritica, L., Escalante, A.A. Herrerra, S and Arevalo-Herrera, M. (2016) Malaria in Pregnancy: A Passive Surveillance Study of Pregnant Women in Low Transmission Areas of Colombia, Latin American. Malaria Journal, 15, 66. https://doi.org/10.1186/s12936-016-1125-9

[14] Ibor, U.W., Okoronkwo, E.M and Rotimi, E.M. (2016) Temporal Analysis of Malaria Prevalence in Cross River State, Nigeria. Journal of Medical Research, 5, 1-7.

[15] Regmi, K., Kunwar, A. and Ortega, L. (2016) A Systematic Review of Knowledge, Attitudes and Beliefs about Malaria among the South Asian Population. Infection, Ecology and Epidemiology, 6, Article ID: 30622. https://doi.org/10.3402/iee.v6.30822

[16] Amase, N., Dayo, E.L., Edogun, A.H. and Akanbi, A.A. (2014) Malaria Parasitaemia among Pregnant Women Possessing Freely Donated Insecticide-Treated Nets (ITNs) in Ado-Ekiti, Nigeria. Global Journal of Biology, Agriculture and Health 
Sciences, 3, 86-91.

[17] Reed, B. and Mena-Moreno, K. (2016) Solid Waste Management. WASH in Emergencies Problem Exploration Report, Humanitarian Innovation Fund.

[18] Lawal, A.M., Balogun, S.K. and Bada, B.V. (2014) Knowledge of Transmission, Malaria Belief and Health Seeking Behavior in Oye-Ekiti Local Government Area of Ekiti State, Nigeria. American Journal of Rural Development, 2, 8-12.

[19] Mahdavi, A. and Habib, F. (2016) Explaining the Role of Cultural, Social and Economic Factors on Quality of Residence in Urban Neighbourhoods: A Case Study of Kerman. Journal of Geography and Regional Planning, 9, 59-69. https://doi.org/10.5897/JGRP2016.0559

[20] Sativipawee, E., Wong Khang, W., Pattanasin, S., Hoithong, P. and Bhumiratana (2012) Predictors of Malaria-Association with Rubber Plantations in Thailand. BMC Public Health, 12, 1115. https://doi.org/10.1186/1471-2458-12-1115

[21] Mahern, C., Pourette, D., Raboanary, E., Kestaman, T., Piola, P., Randrianarievelojosia, M. and Rogier, C. (2016) Tazomoka Is Not a Problem. Local Perspectives on Malaria Fever, Case Management and Bed Net Use in Madagascar. PLoS ONE, 11, e0151068. https://doi.org/10.1371/journal.pone.0151068

[22] Khan, A.Q., Ali, I., Imran, M., Yasin, M., Abbas, Z., Mufti, F. and Ali, G. (2016) Malaria: Epidemiological Study in Fala Areas of Khyberpukhtunkhwah Pakistan. Professional Medical Journal, 23, 553-558. https://doi.org/10.17957/TPMJ/16.3189

[23] Abate, A., Degarege, A. and Erko, B. (2013) Community Knowledge, Attitude and Practice about Malaria in a Low Endemic Setting of Shewa Robit Town, Northeastern Ethiopia. BMC Public Health, 13, 312.

[24] Myers, S.S. and Patz, J.A. (2009) Emerging Threats to Human Health from Global Environmental Change. Annual Review of Environmental Resources, 34, 223-252. https://doi.org/10.1146/annurev.environ.033108.102650

[25] Musoke, D., Musoke, M.B. and Nsubuga, W. (2014) Factors Associated with Prevention of Malaria and Other Diseases Transmitted by Mosquitoes at Household Level in Wakiso District, Uganda. Journal of Environmental Health Research, 13, 59-67. http://www.cieh.org/jehr/default.aspx?id=50264

[26] Obi, Z., Anyaegbunam, L. and Emmy-Egbe, O. (2014) Human Practices-A Case in Breeding of Mosquito Vectors in Ekwulobia, Anambra State Nigeria. Journal of Entomology and Zoology Studies, 2, 190-193.

[27] Kabbale, F.G., Akol, A.M., Kaddu, J.B. and Onapa, A.W. (2013) Biting Patterns and Seasonality of Anopheles gambiae sensulato and Anopheles funestus Mosquitoes in Kamuli District, Uganda. Parasites and Vectors, 6, 340. https://doi.org/10.1186/1756-3305-6-340

[28] Oresanya, O.B., Hoshen, M. and Sofola, O.T. (2008) Utilization of Insecticide-Treated Nets by Under-Five Children in Nigeria: Assessing Progress towards the Abuja Targets. Malaria Journal, 7, 145. https://doi.org/10.1186/1475-2875-7-145

[29] Diro, G.M., Affognon, H.D., Muriithi, B.W., Wanja, S.K., Mbogo, C. and Mutero, C. (2016) The Role of Gender on Malaria Preventive Behavior among Rural Households in Kenya. Malaria Journal, 15, 14.

[30] Amponsah, E.N. (2010) Mothers' Demand for Preventive Healthcare for Children Aged Under-Five Years: The Case of Utilization of Insecticide-Treated Bed Nets in Ghana. Journal of Sustainable Development, 3, 98-106. http://www.ccsenet.org/journal/index.php/jsd/article/download/.../5061

[31] Noor, A.M., Kirui, V.C., Brooker, S.J. and Snow, R.W. (2009) The Use of Insecticide 
Treated Nets by Age: Implications for Universal Coverage in Africa. BMC Public Health, 9, 369. https://doi.org/10.1186/1471-2458-9-369

[32] Iwu, R.U., Ijioma, B.C., Egeruoh, A.S., Awurum, I.N. and Ohakele, C.N. (2010) Awareness and Use of Insecticide Treated Nets among Pregnant Women Attending Antenatal Clinic at Federal Medical Center and General Hospital Owerri, Imo State. Report and Opinion, 2, 154-157.

[33] Adebayo, A.M., Akinyemi, O.O. and Cadmus, E.O. (2015) Knowledge of Malaria Prevention among Pregnant Women and Female Caregivers of Under-Five Children in Rural Southwestern Nigeria. PeerJ, 3, e792.

[34] Erhabo, O., Adias, T.C. and Hart, M.L. (2009) Effects of Falciparum Malaria on the Indices of Anaemia among Pregnant Women in the Niger Delta of Nigeria. Journal of Clinical Medicine and Research, 2, 35-41.

[35] Legesse, M. and Deressa, W. (2009) Community Awareness about Malaria, Its Treatment and Mosquito Vector in Rural Highlands of Central Ethiopia. Ethiopian Journal of Health Development, 23, 40-47. https://doi.org/10.4314/ejhd.v23i1.44836

[36] Breiger, W. (2016) How Can We End Malaria for Good if We Cannot Identify It? African Health.

[37] Obol, J., Kitara, D.L. and Orach, C.G. (2011) Knowledge and Misconceptions about Malaria among Pregnant Women in a Post-Conflict Internally Displaced Persons' Camp in Gulu District, Northern Uganda. Malaria Research and Treatment, 2011, Article ID: 107987.

[38] Aluko, J.O. and Oluwatosin, A.O. (2012) Utilization of Insecticide Treated Nets during Pregnancy among Postpartum Women in Ibadan, Nigeria: A Cross-Sectional Study. BMC Pregnancy and Childbirth, 12, 21. https://doi.org/10.1186/1471-2393-12-21

[39] Anchang-Kimbi, J.K., Achidi, E.A., Apinjoh, T.O., Mugri, R.N., Chi, H.F., Tata, R.B., Nkegourn, B., Mendimi, J.N., Sverremark-Ekstrom, E. and Troye-Blomberg, M. (2014) Antenatal Care Visit, IPT during Pregnancy (IPTp) and Malaria Parasitaemia at Delivery. Malaria Journal, 13, 162. https://doi.org/10.1186/1475-2875-13-162 